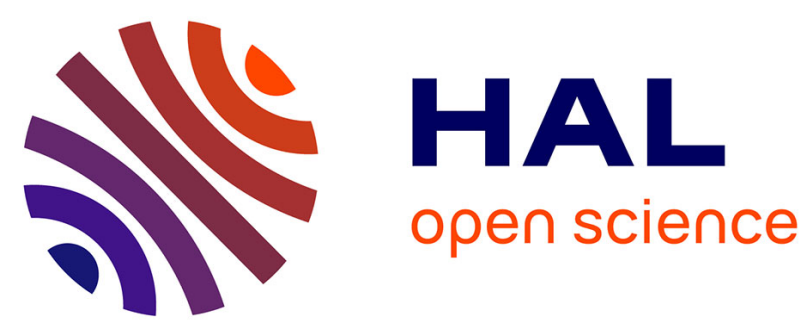

\title{
From biodiversity to catalytic diversity: how to control the reaction mechanism by the nature of metallophytes
}

Vincent Escande, Tomasz Olszewski, Claude Grison

\section{To cite this version:}

Vincent Escande, Tomasz Olszewski, Claude Grison. From biodiversity to catalytic diversity: how to control the reaction mechanism by the nature of metallophytes. Environmental Science and Pollution Research, 2015, Combining Phytoextraction and Ecological Catalysis: an Environmental, Ecological, Ethic and Economic Opportunity, 22 (8), pp.5653 - 5666. 10.1007/s11356-014-3483-6 . hal-01937604

\section{HAL Id: hal-01937604 \\ https://hal.umontpellier.fr/hal-01937604}

Submitted on 23 Feb 2021

HAL is a multi-disciplinary open access archive for the deposit and dissemination of scientific research documents, whether they are published or not. The documents may come from teaching and research institutions in France or abroad, or from public or private research centers.
L'archive ouverte pluridisciplinaire HAL, est destinée au dépôt et à la diffusion de documents scientifiques de niveau recherche, publiés ou non, émanant des établissements d'enseignement et de recherche français ou étrangers, des laboratoires publics ou privés. 


\title{
From biodiversity to catalytic diversity: how to control the reaction mechanism by the nature of metallophytes
}

\author{
Vincent Escande • Tomasz K. Olszewski • Claude Grison
}

Received: 29 May 2014 / Accepted: 18 August 2014

(C) Springer-Verlag Berlin Heidelberg 2014

\begin{abstract}
Phytoextraction is widely used for the reclamation of degraded sites, particularly to remove trace metals from contaminated soils. Whereas this technique demonstrates several advantages, the biomass resulting from phytoextraction processes is highly enriched in metallic elements and constitutes therefore a problematic waste. We show here that this biomass can be used for the preparation of novel polymetallic extracts, with high potential as catalysts or reagents in organic synthesis. This new concept of ecocatalysis constitutes an innovative recycling of metallic elements whose current known reserves could be exhausted in the coming decades. The ecocatalysts Eco-Zn and Eco-Ni prepared respectively from $\mathrm{Zn}$ and Ni hyperaccumulating plants display two distinct chemical reactivities, starting from the same substrates. Eco$\mathrm{Zn}$ led to the formation of esters of commercial interest for the fragrance industry, following a hydro-acyloxy-addition reaction pathway. In contrast, Eco-Ni afforded chlorinated products thank to the hydrochlorination of alkenes. Both ecocatalysts allowed the synthesis of valuable products in high yields through methodologies in line with the spirit of sustainable chemistry.
\end{abstract}

Keywords Phytoextraction · Green chemistry · Ecocatalysis · Lewis acid catalysis $\cdot$ Metal-hyperaccumulating plants . Chemodiversity

Responsible editor: Philippe Garrigues

V. Escande $\cdot$ C. Grison $(\bowtie)$

FRE 3673 - Bioinspired chemistry and ecological innovation -

CNRS, University of Montpellier 2, Stratoz - Cap Alpha, Avenue de l'Europe, 34830 Clapiers, France

e-mail: claude.grison@cnrs.fr

T. K. Olszewski

Faculty of Chemistry, Wroclaw University of Technology, Wybrzeze Wyspianskiego 27, 50-370 Wroclaw, Poland

\section{Introduction}

Phytoextraction of trace metals: environmental opportunities and innovative sustainable chemistry

The depletion of world reserves of metals has become a very serious problem, both from an economic and environmental point of view (Hunt et al. 2013). Due to an increasing demand for consumer goods and the continuous increase of the world population, there is a risk that the available reserves of many metals, widely used in industry, will be exhausted in less than 50 years (Hunt et al. 2013; Salazar 2013). Among those metals threatened with depletion, many of them are frequently used in synthetic industrial processes as catalysts. This is particularly the case of zinc, nickel, manganese, and platinum group elements (PGE) (Lloyd 2011; Yamamoto 2000). To cope with these risks of depletion, new recycling strategies are implemented (United Nations Environment Programme (UNEP) and United Nations University 2009), but today many metals are still recycled in less than $50 \%$ (Hunt et al. 2013). Moreover, the need to maintain a constant supply of these metallic resources leads metal mining industry to develop new operations, which is a source of environmental and social impacts of high concern (Bridge 2004; Thornton 1996).

On the other hand, to remedy soil pollution caused by mining, phytoremediation programs have been developed in many countries (Chaney et al. 2000; Raskin and Ensley 2000; Singh et al. 2003). Among the techniques used in phytoremediation, the phytoextraction is often applied, a technique that relies on the use of so-called metalhyperaccumulating plants or metallophytes, able to extract metallic trace elements (trace metals, TM) from the soil and concentrate them in their leaves (Anderson 2013). Phytoremediation processes are now among the most frequently used to restore the former mining sites, because of 
their low cost of implementation, low environmental impact, and good public acceptance (Bhargava et al. 2012). However, numerous efforts are still necessary to exploit the ability of recovering and recycling metals from contaminated biomass produced during phytoextraction and fully develop the economic potential of this technique. Thus, innovative technologies are needed to receive the full benefit of the remediation process.

The existence of the aforementioned problems, namely pollution caused by the mining industry on the one hand and the depletion of metallic resources on the other hand, has led us to seek a solution to enhance the utility of the biomass issued from the phytoextraction processes and to improve the resulting economic opportunities. Therefore, we have developed a new range of catalysts for use in organic synthesis, called "ecocatalysts," from biomass rich in metallic elements accumulated in the plant tissue issued after phytoextraction (Grison and Escarré 2011; Grison and Escande 2013a, b; 2014).

Use of the ecocatalysts in synthesis of valuable products for the fine chemical industry

Herein, we show the synthetic potential of ecocatalysts, underlying the fact that it is possible to control the reaction mechanism by choosing the right type of ecocatalyst, and the nature of metallophyte from which it derives. Thus, the presented here ecocatalysts Eco-Zn or Eco-Ni may promote different reaction pathways, based on the same substrates. These examples illustrate the importance of ecocatalysts in organic synthesis and the diversity of products possible to obtain according to ecocatalyst used. The catalysts used in this study are generated from biomass, issued from metal-hyperaccumulating plants, using the procedure discovered in our laboratory (Grison and Bès 2013; Saunier et al. 2013).

Eco-Zn was prepared from biomass derived from hyperaccumulating plants grown in France (Saint-Laurentle-Minier, Gard) in order to restore old zinc mining sites. The catalyst Eco-Ni was prepared from nickelhyperaccumulating plants grown in New Caledonia (South province), on sites degraded by the nickel mining industry. We sought to use these catalysts in chemical reactions of high economic interest and particularly for industrial production of fine chemicals.

At present, the chemical industry is changing to adapt its processes to new environmental requirements (Adams et al. 2013; Matus et al. 2010; Wilson and Schwarzman 2009). This transition towards new eco-compatible processes is particularly desirable in the field of fine chemicals, which produces large amounts of waste per kilogram of final product and use solvents, reagents, catalysts, and toxic pollutants (Federsel 2013; Watson 2012).
More specifically, the industrial sector of fragrances and cosmetics appears to be very concerned about the environmental compatibility of its processes, in particular for reasons of communication vis-à-vis its customers (Dobbs et al. 2000; Kraft et al. 2005; Leseurre et al. 2014).

Catalysis of the hydro-acyloxy-addition reaction: context and advantages of the use of ecocatalysts

Due to the high potential of our ecocatalysts as Lewis acids, revealed in our previous works (Escande et al. 2014a, 2014b, 2014c; Grison et al. 2013), we became interested in the hydro-acyloxy-addition reaction known to produce valuable products under Lewis acid catalysis (Wunderly and Sowa 1937). This reaction is the source of many starting materials for the industry of perfumes and cosmetics, including verdyl acetate issued from dicyclopentadiene (Sell 2006), commercialized by Givaudan under the name Jasmacyclene $^{\circledR}$ (Fig. 1).

A detailed study of this reaction has been published in various articles by Peterson and co-workers (Peterson 1960; Peterson and Allen 1962, 1963; Peterson and Tao 1964). Thus, the use of different catalysts for that transformation was reported thus far in the literature such as follows: boron trifluoride (Wunderly and Sowa 1937), Pdand Ti(III)-based catalysts (Annby et al. 1993; Ferraz and Ribeiro 1992; Larock and Hightower 1993), sulfamic acid (Wang et al. 2004), triflic acid (Li et al. 2006; Rosenfeld et al. 2006), ferric triflate (Choi et al. 2008), copper(II) triflate (Taylor et al. 2005), indium(III) triflate (Chen and Lu 2007), cerium(IV) sulfate (Horiuchi et al. 2003), and ionic liquids ( $\mathrm{Gu}$ et al. 2004). Although these systems effectively catalyze the hydro-acyloxy-addition reaction, they have certain drawbacks such as the use of metals whose reserves will be exhausted in the coming decades, the necessity of handling hazardous reagents and pollutants or the use of non-environmentally friendly solvents and nonreusable catalysts. Some improvements have been made by the use of heterogeneous catalysis supported on montmorillonite (Ballantine et al. 1981; Yang et al. 2006) and silica gel (Hinze et al. 2009). These applications, however, are substrate-dependent and provide products with moderate yields. The development of efficient and reusable catalytic systems based on abundant resources and the handling of which represents no risk for the environment is therefore highly desirable.

The characteristics of our ecocatalysts Eco-Zn and Eco-Ni perfectly meet these requirements. Additionally, this study highlights an unexpected reaction pathway, leading to different products starting from the same substrates, by simply changing the polymetallic composition of the ecocatalysts prepared from biomass from different metal-hyperaccumulating plants. 
Fig. 1 Starting materials for fragrance industry prepared via hydro-acyloxy-addition reaction from dicyclopentadiene

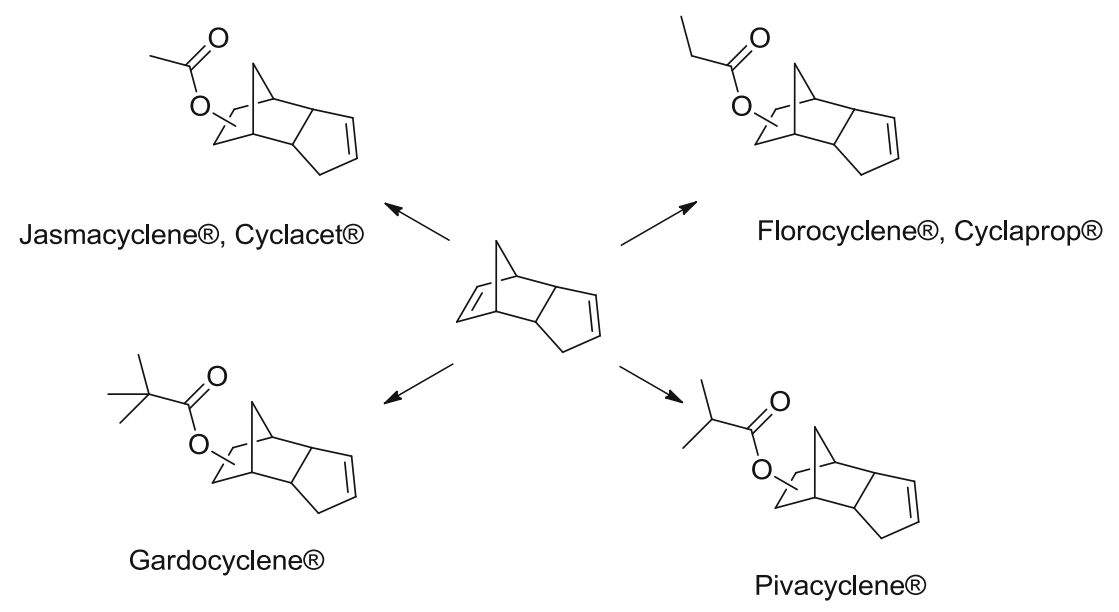

\section{Materials and methods}

Preparation of ecocatalysts

\section{Eco-Zn from Zn hyperaccumulating plants}

Leaves of Noccaea caerulescens (Brassicaceae) and Anthyllis vulneraria (Fabaceae) were harvested before flowering in Les Avinières, a former zinc mining site in Saint-Laurent-LeMinier, southern France (same mass of the two plants), airdried and crushed. The obtained solid ( $30 \mathrm{~g})$ was heated to $400{ }^{\circ} \mathrm{C}$ for $5 \mathrm{~h}$ and the resulting powder $(5 \mathrm{~g})$ was added to $50 \mathrm{~mL}$ of $1 \mathrm{M} \mathrm{HCl}$ solution. The solution was heated at $60^{\circ} \mathrm{C}$ and stirred for $2 \mathrm{~h}$. The reaction mixture was filtered on a pad of celite. The resulting yellow solution, composed of different metal chlorides, was then concentrated under vacuum, yielding Eco-Zn (5.1 g). The catalyst was kept in a desiccator under vacuum.

\section{Eco-Ni from Ni-hyperaccumulating plants}

Leaves of Geissois pruinosa (Cunoniaceae) were harvested in the South province of New Caledonia, on Chemin de Prony, near Noumea. The leaves were air-dried and crushed, then the obtained solid ( $42 \mathrm{~g}$ ) was heated to $400{ }^{\circ} \mathrm{C}$ for $5 \mathrm{~h}$ and the resulting powder $(5 \mathrm{~g})$ was added to $50 \mathrm{~mL}$ of $1 \mathrm{M} \mathrm{HCl}$ solution. The solution was heated at $60{ }^{\circ} \mathrm{C}$ and stirred for $2 \mathrm{~h}$. The reaction mixture was filtered on a pad of celite. The resulting green solution, composed of different metal chlorides, was then concentrated under vacuum, yielding Eco-Ni $(3.38 \mathrm{~g})$. The catalyst was kept in a desiccator under vacuum.

\section{Characterization of ecocatalysts}

Inductively coupled plasma mass spectrometry (ICP-MS) analyses were performed using the metal analysis of total dissolved solutes in water. The samples were acidified with nitric acid $2.5 \%$ and stirred for $30 \mathrm{~min}$. The digestates were diluted to 0.005 g. $\mathrm{L}^{-1}$. Three blanks were recorded for each step of the digestion and dilution procedure on a HR-ICP-MS Thermo Scientific Element XR. Three analyses were performed for each sample in order to determine the standard deviation of the measurement.

X-ray diffraction (XRD) data measurements on the samples dried at $110{ }^{\circ} \mathrm{C}$ for $2 \mathrm{~h}$ were performed by using a BRUKER diffractometer (D8 advance, with a $\mathrm{CuK} \alpha$ radiation $\lambda=1.54086^{\circ} \mathrm{A}$ ) equipped with a LynxEye detector.

FT-IR measurements were carried out using pyridine as probe molecule. A PerkinElmer Spectrum 100 FT-IR spectrometer was used for recording the spectra. Excess gaseous pyridine was adsorbed on the samples, then the samples were degassed for $15 \mathrm{~min}$ at $25^{\circ} \mathrm{C}\left(10^{-3} \mathrm{~Pa}\right)$ and a first spectrum was recorded. The samples were then degassed for $15 \mathrm{~min}$ at $150{ }^{\circ} \mathrm{C}\left(10^{-3} \mathrm{~Pa}\right)$ in order to eliminate the physisorbed pyridine and a second spectrum was recorded.

The use of ecocatalysts Eco-Zn and Eco-Ni in organic synthesis

\section{Chemicals}

Reagents and solvents were purchased from Sigma-Aldrich, and were used without further purification.

\section{Purification and analysis of reaction products}

Flash column chromatography was performed using Chromagel Carlo Erba Reactifs SDS silica 60 A CC 35$70 \mu \mathrm{m}$. Reactions were monitored using Merck Kieselgel 60 F254 aluminum. TLCs were visualized by UV fluorescence $(254 \mathrm{~nm})$ then by immersion in one of the following dyeing reagents: $\mathrm{KMnO}_{4}$, vanillin, ninhydrin, phosphomolybdic acid solution, and phosphotungstic acid solution.

NMR spectra were recorded on a Brüker Avance 300 spectrometer at room temperature, ${ }^{1} \mathrm{H}$ frequency is at $300 \mathrm{MHz}$ and ${ }^{13} \mathrm{C}$ frequency is at $75 \mathrm{MHz}$. IR spectra were 
recorded on a PerkinElmer Spectrum 100 FT-IR spectrometer, in ATR mode. GC-MS analyses were performed on a Shimadzu QP2010SE apparatus, equipped with a $30 \mathrm{~m} \times$ $0.25 \mathrm{~mm} \times 0.25 \mu \mathrm{m}$ ZB-5MSi Guardian column $\left(\right.$ Phenomenex ${ }^{\circledR}$ ) with hydrogen as carrier gas.

\section{General procedure}

All reactions were conducted in sealed vials $(4 \mathrm{~mL})$ equipped with magnetic stirring. Silica (1.0 g, Chromagel Carlo Erba Reactifs SDS silica 60 A CC 35-70 $\mu \mathrm{m})$, carboxylic acid, alkene, and ecocatalyst (Eco-Zn or Eco-Ni, mass corresponding to amounts indicated in Tables 5, 6, 7) were mixed by grinding in a mortar. The resulting solid was introduced in a sealed vial and heated to $120{ }^{\circ} \mathrm{C}$ in sand bath for 2-24 h. Aliquots were taken for analysis in GC-MS and TLC, after dilution in dichloromethane. After completion of the reaction, the solid was washed with cyclohexane $(3 \times 5 \mathrm{~mL})$ and filtered. The resulting solution was concentrated under reduced pressure and purified by flash column chromatography. The previous catalytic solid (mixture of ecocatalyst and silica) was recycled by washing with cyclohexane and drying in an oven $\left(120^{\circ} \mathrm{C}, 5 \mathrm{~h}\right)$, before being reused in the next run.

Synthesized products were identified by comparing their spectroscopic data (IR, ${ }^{1} \mathrm{H}$ NMR, ${ }^{13} \mathrm{C}$ NMR, MS) with those previously published (He and Goldsmith 2010; Magens et al. 2007; Schmidt et al. 1980; Taylor et al. 2005; Wang et al. 2004) or with those of authentic commercial samples. When necessary, the exact position of the introduced substituent was determined by key Heteronuclear Multiple Bond Correlation (HMBC) correlations or by 2D total correlation spectroscopy (TOCSY) experiments.

\section{Results and discussion}

Characterization of Eco-Zn and Eco-Ni ecocatalyst

After harvest, the $\mathrm{Zn}$ hyperaccumulating plants $N$. caerulescens (Brassicaceae) and A. vulneraria (Fabaceae) were transformed into Eco-Zn following a procedure designed to be simple to implement. After air drying and thermic treatment at $400{ }^{\circ} \mathrm{C}$, to remove most of the organic matter, and addition of $1 \mathrm{M}$ hydrochloric acid followed by concentration of the resulting solution, a mixture of a polymetallic salts was obtained. Analogous procedure was followed for biomass from the Ni-hyperaccumulating plant $G$. pruinosa (Cunoniaceae). The Eco-Zn and Eco-Ni were characterized by ICP-MS analysis and XRD techniques. Their Lewis acidity was studied by infrared monitoring of the adsorbed pyridine.

\section{ICP-MS analysis}

ICP-MS analysis of Eco-Zn The mineral analysis of Eco-Zn was performed by ICP-MS after dilution of the solid in an aqueous solution of $2.5 \%$ nitric acid (Table 1). The results of the analysis revealed that $\mathrm{Zn}$ is the main transition metal present in the analyzed polymetallic composition of Eco-Zn (6.57 wt \%), and is accompanied mostly by $\mathrm{Fe}(1.80 \mathrm{wt} \%)$ and $\mathrm{Al}(1.74 \mathrm{wt} \%)$ (Table 1).

The reproducibility of the composition of Eco-Zn was studied in our previous article, which showed that the levels of transition elements are only slightly variable between samples of Eco-Zn prepared from batches of different plants (Escande et al. 2014c). Eco-Zn was prepared from most representative batches of the plants to homogenize the content of the transition elements and minimize possible variations in their composition.

ICP-MS analysis of Eco-Ni Analogous procedure using ICPMS was employed to characterize the Eco-Ni catalyst (Table 2).

The analysis showed that $\mathrm{Ni}$ is the major transition metal present in the Eco-Ni catalyst (7.39 wt\%). Small amounts of other transition metals were also observed, but at much lower levels than in the case of Eco-Zn: Fe (0.79 wt\%), Mn $(0.16 \mathrm{wt} \%)$, and $\mathrm{Zn}(1.25 \mathrm{wt} \%)$. The amount of $\mathrm{Al}$ present was in the range of $0.53 \mathrm{wt} \%$ whereas the content of $\mathrm{Mg}$ (7.63 wt\%) was comparable to that observed for Eco-Zn. In turn, the amounts of $\mathrm{Ca}(11.98 \mathrm{wt} \%)$ were two to three times lower than those observed in the case of Eco-Zn.

\section{XRD analysis}

$X R D$ analysis of Eco-Zn The X-ray diffraction (XRD) analysis of Eco-Zn showed crystalline species present in the solid (Fig. 2). Various chlorides have been characterized, including the mixed chloride $\mathrm{CaMg}_{2} \mathrm{Cl}_{6}\left(\mathrm{H}_{2} \mathrm{O}\right)_{12}$ and $\mathrm{K}_{2} \mathrm{ZnCl}_{4}$ and potassium chloride $\mathrm{KCl}$ (Table 3). $\mathrm{K}_{2} \mathrm{ZnCl}_{4}$ is a masked form of $\mathrm{ZnCl}_{2}$ as shown in our previous work (Escande et al. 2014a). The presence of other species not detectable by XRD is very likely, since this technique does not reveal the presence of molecules containing, e.g., $\mathrm{Fe}$ or $\mathrm{Al}$, detected by the elemental analysis. This is probably due to the non-crystalline nature of these species within the Eco-Zn catalyst, which did not allow their characterization by XRD.

$X R D$ analysis of Eco-Ni The XRD analysis of Eco-Ni catalyst revealed the presence of several mixed chlorides: $\mathrm{CaMg}_{2} \mathrm{Cl}_{6}\left(\mathrm{H}_{2} \mathrm{O}\right)_{12}$ (also detected in the Eco-Zn catalyst), $\mathrm{KCaCl}_{3}$, and $\mathrm{KNiCl}_{3}$ (Fig. 3 and Table 4). $\mathrm{KNiCl}_{3}$ is a masked form of $\mathrm{NiCl}_{2}$, having interesting Lewis acidic properties and potential for use in organic synthesis. Several sulfates were also detected, including $\mathrm{NiSO}_{4}\left(\mathrm{H}_{2} \mathrm{O}\right)_{6}$ and $\mathrm{Na}_{2} \mathrm{SO}_{4}$. This 
Table 1 ICP-MS analysis of Eco-Zn

\begin{tabular}{lllllllll}
\hline Ecocatalyst & $\begin{array}{l}\text { Latitude and longitude } \\
\text { data of sampling site }\end{array}$ & $\begin{array}{l}\mathrm{Mg} \\
\mathrm{wt} \%( \pm \mathrm{SD})\end{array}$ & $\begin{array}{l}\mathrm{Ca} \\
\mathrm{wt} \%( \pm \mathrm{SD})\end{array}$ & $\begin{array}{l}\mathrm{Fe} \\
\mathrm{wt} \%( \pm \mathrm{SD})\end{array}$ & $\begin{array}{l}\mathrm{Zn} \\
\mathrm{wt} \%( \pm \mathrm{SD})\end{array}$ & $\begin{array}{l}\mathrm{Cd} \\
\mathrm{wt} \%( \pm \mathrm{SD})\end{array}$ & $\begin{array}{l}\mathrm{Al} \\
\mathrm{wt} \%( \pm \mathrm{SD})\end{array}$ & $\begin{array}{l}\mathrm{Pb} \\
\mathrm{wt} \%( \pm \mathrm{SD})\end{array}$ \\
\hline Eco-Zn & $43.933031,3.666407$ & $\begin{array}{l}3.76 \\
( \pm 0.10)\end{array}$ & $\begin{array}{l}35.81 \\
( \pm 0.50)\end{array}$ & $\begin{array}{l}1.80 \\
( \pm 0.028)\end{array}$ & $\begin{array}{l}6.57 \\
( \pm 0.059)\end{array}$ & $\begin{array}{l}0.35 \\
( \pm 0.0040)\end{array}$ & $\begin{array}{l}1.74 \\
( \pm 0.049)\end{array}$ \\
\hline
\end{tabular}

observation is consistent with the high levels of sulfate ion observed in G. pruinosa, as described in our previous article (Grison et al. 2013). In turn, the presence of potassium chlorate is difficult to explain. Such an inorganic species have been observed previously in similar ecocatalysts (Escande et al. 2014a). A possible explanation can be that the presence of potassium chlorate is due to the decomposition of chlorides during the preparation of the Eco-Ni catalyst, with in situ formation of oxidative species, a fact described in the literature for several transition metal chlorides (Krishna et al. 2003; Mondelli et al. 2011). Thus, the present oxidizing species would then permit the formation of chlorate by oxidation of other salts (Patnaik 2003).

\section{Infrared characterization of the Lewis acidity of Eco-Zn and Eco-Ni by pyridine adsorption}

Characterization of Eco-Zn In order to determine the Lewis acidity of our ecocatalysts, we have used a method that implies, as a probe, pyridine adsorbed on the surface of the examined solid acid, and monitoring the bands in the range of $1,400-1,650 \mathrm{~cm}^{-1}$ arising from its ring vibration modes (Parry 1963; Zaki et al. 2001). Infrared spectra of pyridine adsorbed on crude fraction of our ecocatalysts were recorded at 25 and $150{ }^{\circ} \mathrm{C}$ in order to distinguish frequencies of physisorbed pyridine from frequencies of pyridine coordinated to Lewis sites (Fig. 4).

The presence of weakly bonded pyridine could be attributed to a band at $1,440 \mathrm{~cm}^{-1}$ observed at $25^{\circ} \mathrm{C}$ that disappeared after outgassing at $150{ }^{\circ} \mathrm{C}$ (Fig. 4) (Parry 1963). The first indication of the extract's Lewis acidity was the presence of a band at $1,450 \mathrm{~cm}^{-1}$ at $150{ }^{\circ} \mathrm{C}$, characteristic for pyridine still strongly bonded at this temperature, by coordination to Lewis acid sites (Zaki et al. 2001). The decrease of the band intensity at $1,486-1,487 \mathrm{~cm}^{-1}$ is more delicate to explain. As the intensity was strongly reduced after heating, this band can be attributed to physisorbed pyridine. Looking at bands in the $1,590-1,640 \mathrm{~cm}^{-1}$ region, the band at $1,599 \mathrm{~cm}^{-1}$ observed at $25^{\circ} \mathrm{C}$ disappearing at $150^{\circ} \mathrm{C}$, is characteristic for hydrogenbonded pyridine (Parry 1963). Also, several bands were observed in the 1,600-1,640 $\mathrm{cm}^{-1}$ range, with small variations in frequencies depending on outgassing temperature $(1,608$ and $1,631 \mathrm{~cm}^{-1}$ at $25^{\circ} \mathrm{C} ; 1,609,1,628$, and $1,639 \mathrm{~cm}^{-1}$ at $150{ }^{\circ} \mathrm{C}$ ) (Fig. 4). The continued existence of bands in this region, in spite of heating at elevated temperature, is a proof of the presence of strongly bonded pyridine. Actually, these bands had been attributed to pyridine coordinated to Lewis acid sites, in previous studies. Additionally, their occurrence at different frequencies in this range may account for the involvement of different types of Lewis acid sites (Zaki et al. 2001) and this hypothesis was supported by the previous ICP-MS data (Tables 1 and 2), highlighting the presence of different potential Lewis acids in the extract.

Characterization of Eco-Ni The Eco-Ni catalyst was characterized using the same methodology (Fig. 5). The spectrum taken at $150{ }^{\circ} \mathrm{C}$ shows the persistence of an intense band at $1,447 \mathrm{~cm}^{-1}$, characteristic for the coordination of pyridine to Lewis acid sites. In addition, the Lewis acidity is confirmed by the presence of bands at 1,607 and $1,631 \mathrm{~cm}^{-1}$ still intense after degassing at $150^{\circ} \mathrm{C}$. Knowing that the frequencies of the bands characteristic for the Lewis acidity increases with the strength of the Lewis acid (Parry 1963), allowed us to compare the Eco-Ni with Eco-Zn catalysts in terms of their Lewis acidity. The frequencies of the bands in the region 1,445$1,460 \mathrm{~cm}^{-1}$ and $1,600-1,639 \mathrm{~cm}^{-1}$, observed in the case of the spectrum registered for Eco-Ni catalyst are always lower than those observed in the case of spectrum registered for Eco-Zn. The Lewis acidity of Eco-Ni is therefore lower than the Lewis acidity of Eco-Zn. This is consistent with the expected acidity

Table 2 ICP-MS analysis of Eco-Ni

\begin{tabular}{lllllllll}
\hline Ecocatalyst & $\begin{array}{l}\text { Latitude and longitude } \\
\text { data of sampling site }\end{array}$ & $\begin{array}{l}\mathrm{Mg} \\
\mathrm{wt} \%( \pm \mathrm{SD})\end{array}$ & $\begin{array}{l}\mathrm{Ca} \\
\mathrm{wt} \%( \pm \mathrm{SD})\end{array}$ & $\begin{array}{l}\mathrm{Fe} \\
\mathrm{wt} \%( \pm \mathrm{SD})\end{array}$ & $\begin{array}{l}\mathrm{Ni} \\
\mathrm{wt} \%( \pm \mathrm{SD})\end{array}$ & $\begin{array}{l}\mathrm{Mn} \%( \pm \mathrm{SD}) \\
\mathrm{wt} \%\left(\begin{array}{l}\mathrm{Al} \\
\mathrm{wt} \%( \pm \mathrm{SD})\end{array}\right.\end{array}$ & $\begin{array}{l}\mathrm{Zn} \\
\mathrm{wt} \%( \pm \mathrm{SD})\end{array}$ \\
\hline Eco-Ni & $-22.28417,166.69556$ & $\begin{array}{l}7.63 \\
( \pm 0.013)\end{array}$ & $\begin{array}{l}11.98 \\
( \pm 0.033)\end{array}$ & $\begin{array}{l}0.79 \\
( \pm 0.0050)\end{array}$ & $\begin{array}{l}7.39 \\
( \pm 0.042)\end{array}$ & $\begin{array}{l}0.16 \\
( \pm 0.00042)\end{array}$ & $\begin{array}{l}0.53 \\
( \pm 0.011)\end{array}$ \\
\hline
\end{tabular}


Fig. 2 Characterization of Eco$\mathrm{Zn}$ by XRD

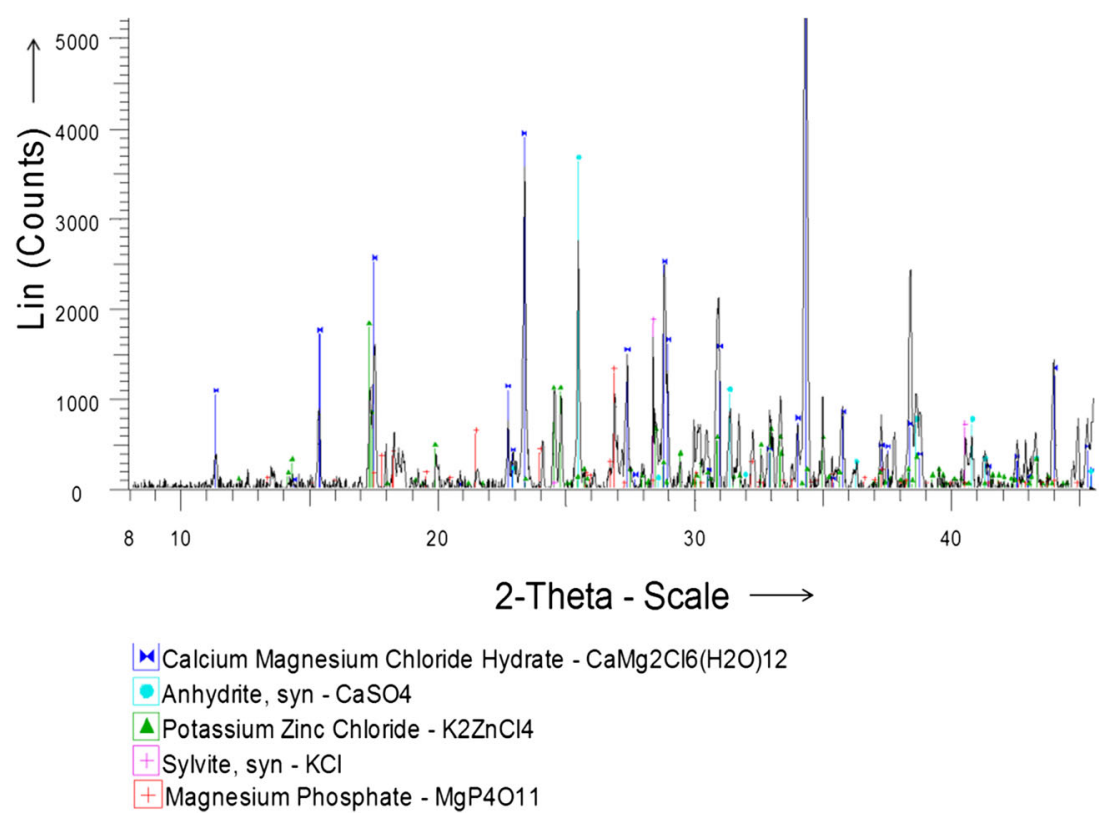

of the main transition metal present in our ecocatalysts, since $\mathrm{Ni}^{2+}$ is a weaker Lewis acid than $\mathrm{Zn}^{2+}$ (Kobayashi et al. 2000; Satchell and Satchell 1969). However, unlike for the Eco-Zn catalyst, the infrared analysis of the adsorbed pyridine on the Eco-Ni catalyst shows the presence of a band at $1,531 \mathrm{~cm}^{-1}$, weak at $25{ }^{\circ} \mathrm{C}$, but very intense after degassing at $150{ }^{\circ} \mathrm{C}$ (Fig. 5). This band has been described as characteristic for the frequency $\nu_{19 b}$ of the pyridinium ion formed by protonation of the pyridine in the presence of Brønsted acid sites (Zaki et al. 2001). The increase of its intensity after degassing at $150{ }^{\circ} \mathrm{C}$ can be connected to the influence of the heating on the kinetics of the protonation of pyridine.

The Eco-Ni catalyst comprises therefore a Lewis acid character, as well as Eco-Zn although slightly lower, and additionally a Brønsted acid character, unobserved in the case of Eco-Zn.

Catalysis of the hydro-acyloxy-addition reaction with Eco-Zn and Eco-Ni ecocatalysts

The hydro-acyloxy-addition reaction has been studied on the model example of condensation of acetic acid (2a) with

Table 3 Crystalline species present in Eco-Zn catalyst and detected by XRD

\begin{tabular}{ll}
\hline Mineral & Formula (simplified) \\
\hline Calcium magnesium chloride hydrate & $\mathrm{CaMg}_{2} \mathrm{Cl}_{6}\left(\mathrm{H}_{2} \mathrm{O}\right)_{12}$ \\
Anhydrite, syn & $\mathrm{CaSO}_{4}$ \\
Potassium zinc tetrachloride & $\mathrm{K}_{2} \mathrm{ZnCl}_{4}$ \\
Sylvite, syn & $\mathrm{KCl}$ \\
Magnesium phosphate & $\mathrm{MgP}_{4} \mathrm{O}_{11}$ \\
\hline
\end{tabular}

dicyclopentadiene (1a), in the presence of our ecocatalysts Eco-Ni or Eco-Zn (Scheme 1).

\section{Reaction catalyzed by Eco-Zn catalyst}

Optimization of reaction conditions was conducted by varying the amounts of acetic acid, Eco-Zn catalyst, as well as the temperature and reaction time (Table 5). At first, reaction with $10 \mathrm{~mol} \%$ of $\mathrm{Zn}$ from Eco-Zn was performed during $4 \mathrm{~h}$ at $120{ }^{\circ} \mathrm{C}$ and gave $87 \%$ of conversion (Table 5, entry 1 ). However, unexpectedly, verdyl acetate $\mathbf{3 a}$ was not the major product, as it was formed only with $37 \%$ yield. A second product was formed, with $50 \%$ yield. After isolation by chromatography on silica gel and characterization by NMR, it was found that the major product of that reaction was the chlorinated compound $\mathbf{4 a}$ (Scheme 2).

The presence of $\mathbf{4 a}$ has not been reported in previous articles describing this reaction thus its formation must be specifically due to the nature of the Eco- $\mathrm{Zn}$ catalyst. By lowering the reaction temperature to $60{ }^{\circ} \mathrm{C}$, the conversion reached only $6 \%$ but 4 a became the major product (Table 5 , entry 2). A comparison was made with $10 \mathrm{~mol} \%$ of $\mathrm{Zn}$ using commercial $\mathrm{ZnCl}_{2}$ (Table 5, entry 3): the conversion was complete, and with a very high selectivity towards verdyl acetate 3a, although traces of chlorinated product $4 \mathbf{a}$ were also observed (around $2 \%$ yield). This confirms that the formation of $\mathbf{4 a}$ is specific to the use of Eco-Zn. Although a high yield of verdyl acetate $3 \mathbf{a}$ could be obtained with the use of commercial $\mathrm{ZnCl}_{2}$, it should be mentioned that this reagent, due to its very hygroscopic nature, is very difficult to handle, which is not observed for Eco-Zn.

Subsequently, in order to improve the conversion rate for the reaction catalyzed by Eco-Zn, heating was continued for $24 \mathrm{~h}$ 
Fig. 3 Characterization of EcoNi by XRD

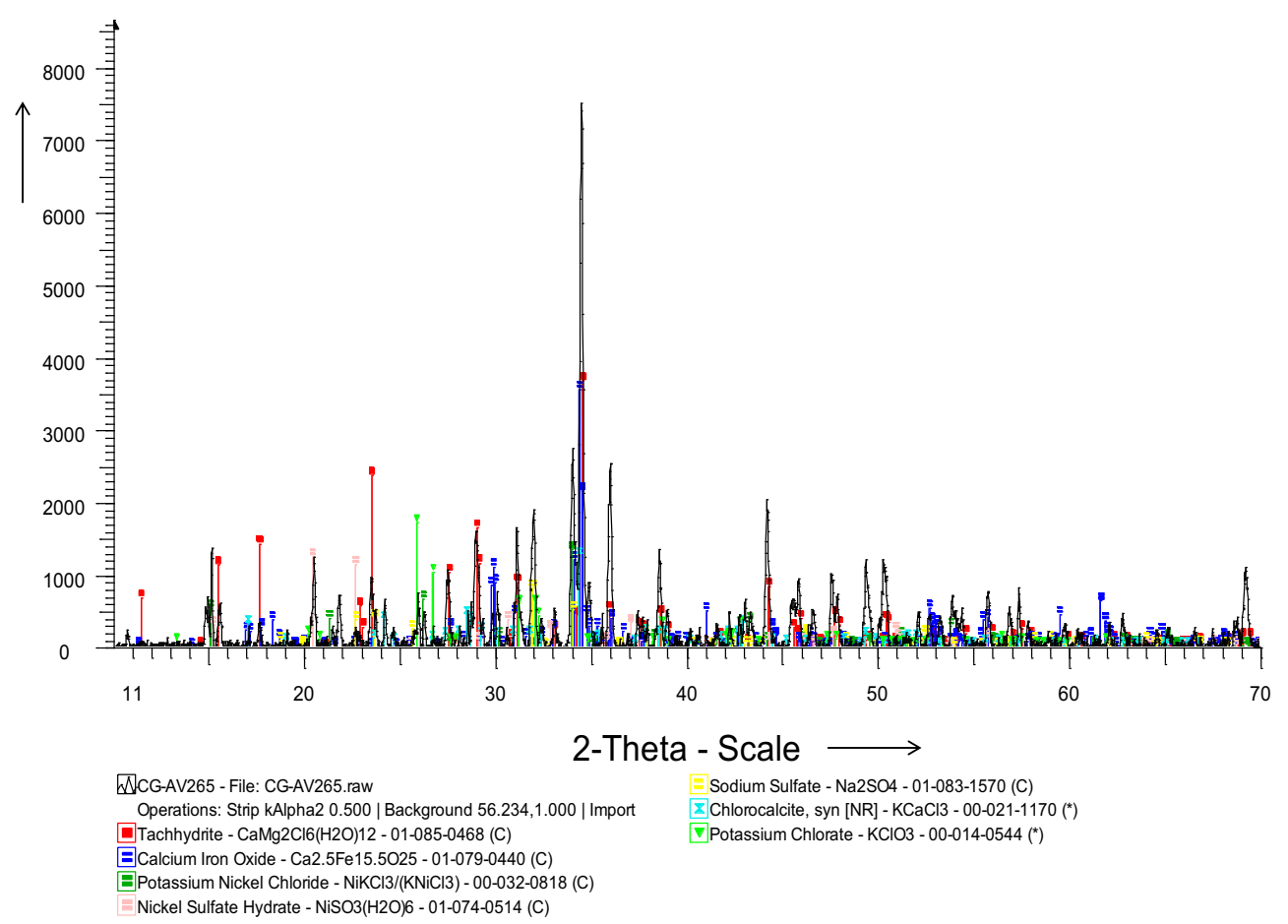

(Table 5, entry 4). Under those conditions, the conversion was almost complete, and verdyl acetate 3a was the major product isolated with $71 \%$ yield. This example shows that the presence of $4 \mathbf{a}$ in the reaction medium is only temporary since it is then obtained with only $28 \%$ yield, whereas when reaction was heated for only 4 h, $\mathbf{4 a}$ is isolated with $50 \%$ yield (Table 5 , entry 1 ).

Importantly, in order to avoid the use of solvent in this reaction, an excess of acetic acid can be employed (3 equivalents) (Table 5, entries 1-5). We sought to reduce the amount of acetic acid to 1 equivalent, while ensuring a good homogeneity of the reaction medium (Table 5, entries 6-10). We studied therefore the reaction in solid phase, using silica as dispersant. The reagents and Eco-Zn catalyst were co-ground in a mortar with silica gel, and the mixture thus obtained was stirred and heated (Table 5, entries 5-10). A first test reaction was performed under the same conditions as above, but with addition of silica gel to verify the influence of the heating of the solid

Table 4 Crystalline species present in Eco-Ni catalyst and detected by XRD

\begin{tabular}{ll}
\hline Mineral & Formula (simplified) \\
\hline Calcium magnesium chloride hydrate & $\mathrm{CaMg}_{2} \mathrm{Cl}_{6}\left(\mathrm{H}_{2} \mathrm{O}\right)_{12}$ \\
Calcium iron oxide & $\mathrm{Ca}_{2.5} \mathrm{Fe}_{15.5} \mathrm{O}_{25}$ \\
Potassium nickel chloride & $\mathrm{KNiCl}_{3}$ \\
Nickel sulfate hydrate & $\mathrm{NiSO}_{4}\left(\mathrm{H}_{2} \mathrm{O}\right)_{6}$ \\
Sodium sulfate & $\mathrm{Na}_{2} \mathrm{SO}_{4}$ \\
Chlorocalcite, syn & $\mathrm{KCaCl}_{3}$ \\
Potassium chlorate & $\mathrm{KClO}_{3}$ \\
\hline
\end{tabular}

reaction medium (Table 5, entry 5). In this case, the complete conversion was observed and the yield of isolated verdyl acetate 3a reached $89 \%$. Furthermore, the reaction time could be reduced from 24 to $12 \mathrm{~h}$. This, methodology proved to be effective in promoting the formation of verdyl acetate and allowed us to reduce the amount of acetic acid to 1 equivalent, while maintaining the high $84 \%$ yield of the desired product 3 a (Table 5, entry 6). It has to mention that the reaction run in the presence of silica gel, without the Eco-Zn catalyst yielded verdyl acetate $\mathbf{3 a}$ in only $17 \%$ yield (Table 5 , entry 7 ).

We then sought to reduce the amount of Eco- $\mathrm{Zn}$ catalyst, since $10 \mathrm{~mol} \%$ can be considered as high $\mathrm{Zn}$ content. The reaction carried out with $1 \mathrm{~mol} \%$ of $\mathrm{Zn}$ from Eco-Zn catalyst provided, on solid phase, $99 \%$ conversion and $87 \%$ yield of isolated verdyl acetate $\mathbf{3 a}$ in just $12 \mathrm{~h}$ (Table 5, entry 8). This shows the effectiveness of Eco-Zn catalyst even at low loading, as the conversion increased from $17 \%$ with the use of just silica gel (Table 5, entry 7) to $99 \%$ with $1 \mathrm{~mol} \%$ of $\mathrm{Zn}$ from Eco-Zn catalyst (Table 5, entry 8 ). In addition, recycling tests of the catalytic medium silica gel/Eco-Zn catalyst were performed (Table 5, entries 9 and 10). Washing with cyclohexane, filtration and drying in an oven $\left(120^{\circ} \mathrm{C}, 5 \mathrm{~h}\right)$ of the solid phase at the end of reaction provide the recycled catalytic system. Other solvents in which the metal chlorides present in the Eco$\mathrm{Zn}$ catalyst are not soluble can also be used instead of cyclohexane. For example, ethyl acetate proved equally effective to wash the solid phase. After recycling the solid phase containing Eco-Zn, we used it again in the reaction under the same conditions as describe above, and only slight decrease in the conversion was detected (Table 5, entries 9 and 10). 
Fig. 4 IR spectra of pyridine adsorbed on Eco-Zn, after brief outgassing at the indicated temperatures

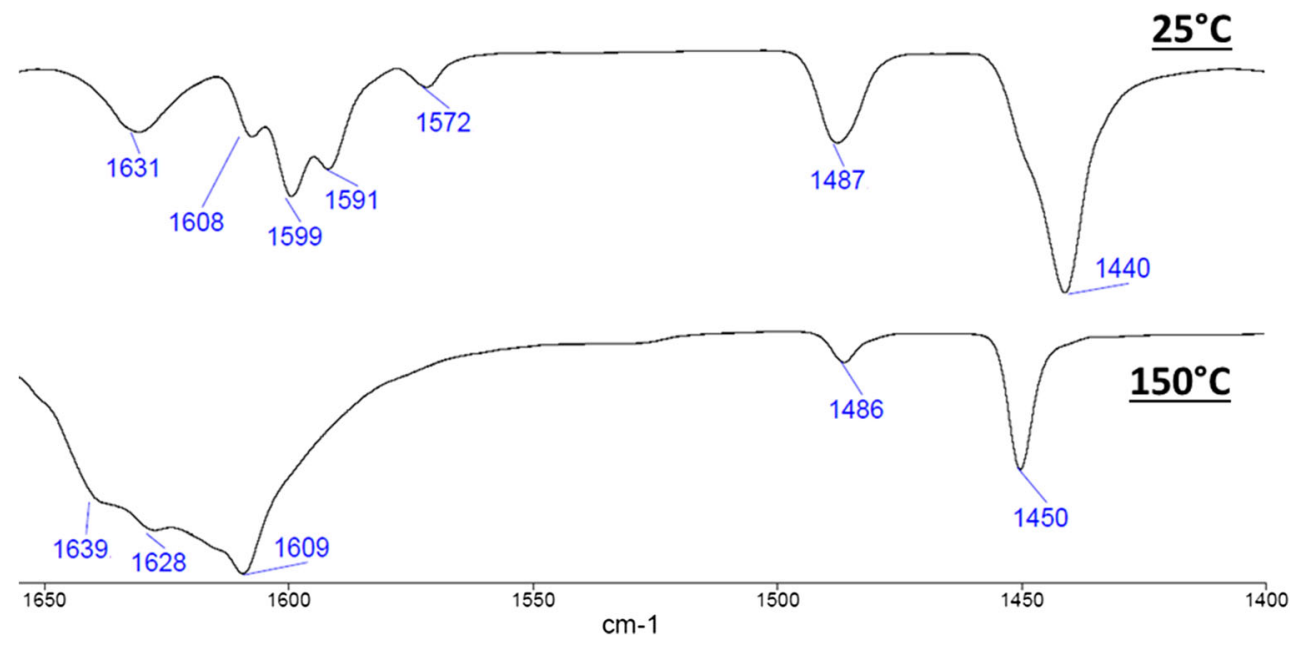

\section{Reaction catalyzed by Eco-Ni catalyst}

The IR studies described earlier revealed a significant difference between the Eco-Zn and Eco-Ni catalytic systems. EcoNi catalyst shows a lower Lewis acidity than Eco-Zn; however, it demonstrates a strong Brønsted acid character. It seemed therefore interesting to compare the activity of both catalytic systems in the hydro-acyloxy-addition reaction of acetic acid (2a) with dicyclopentadiene (1a).

The Eco-Ni catalyst was first tested in the reaction under similar conditions as it was for Eco-Zn: loading $10 \mathrm{~mol} \%, 4 \mathrm{~h}$ reaction time at $120{ }^{\circ} \mathrm{C}$. Under these conditions, the conversion observed was $58 \%$ (Table 6 , entry 1 ), which is less than the conversion observed previously with Eco-Zn $(87 \%$, Table 5, entry 1). This result can be explained by the lower Lewis acidity of Eco-Ni compared to Eco-Zn catalyst. It is therefore in agreement with the IR study of the two ecocatalysts. However, the proportion of chlorinated product 4a versus verdyl acetate 3a was higher with the use of Eco-Ni (4a/3a: 44/14) than with the Eco-Zn (4a/3a: 50/37). This result can also be connected with the data obtained during infrared characterization of the Lewis acidity by pyridine adsorption ("Infrared characterization of the Lewis acidity of Eco-Zn and Eco-Ni by pyridine adsorption" section). Unlike Eco-Zn, the Eco-Ni catalyst showed a significant Brønsted acid character, probably due to the presence of $\mathrm{HCl}$ linked to this catalyst. A clear evidence supporting this assumption is the tendency of Eco-Ni to promote hydrochlorination of alkenes. Thus with Eco-Ni, having a lower Lewis acidity than Eco-Zn catalyst, the formation of verdyl acetate $\mathbf{3 a}$ remains a secondary reaction. The structure of the Eco-Ni is therefore ideal to promote the formation of the chlorinated product $4 \mathbf{a}$.
Fig. 5 IR spectra of pyridine adsorbed on Eco-Ni, after brief outgassing at the indicated temperatures
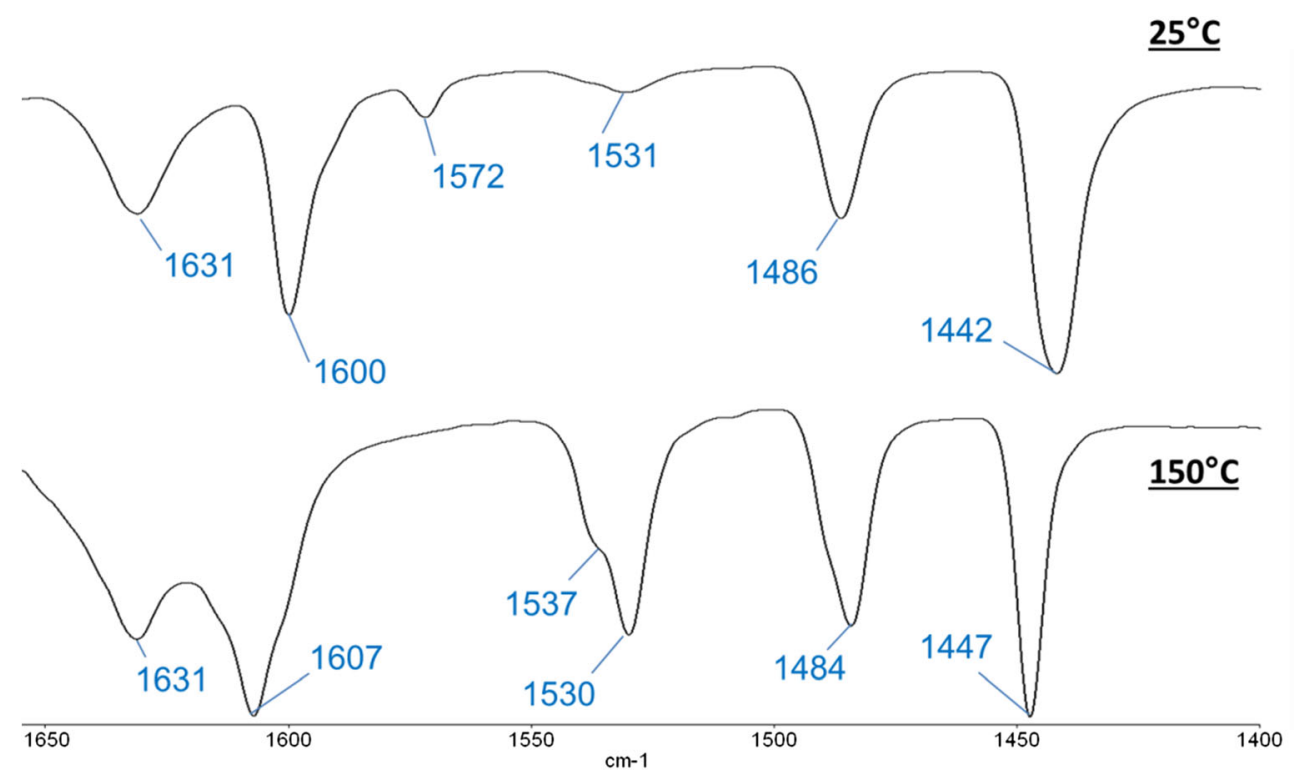
Scheme 1 Hydro-acyloxyaddition reaction catalyzed by the ecocatalysts
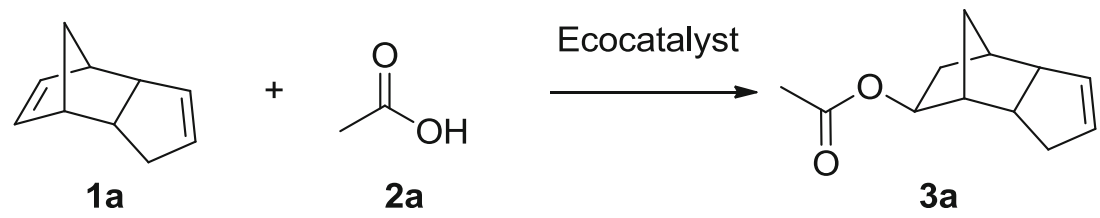

Due to the selectivity observed with Eco-Ni, we looked at whether it is possible to obtain more selectively the chlorinated product 4a. Unlike the reaction where verdyl acetate $\mathbf{3 a}$ is formed as the major product, the synthesis of chlorinated compound 4a requires the use of Eco-Ni not only as the catalyst but also as a reagent, a source of $\mathrm{Cl}$. Therefore, we increased the amount of Eco-Ni, using 1 equivalent of $\mathrm{Ni}$ from Eco-Ni. We also reduced the reaction time to $2 \mathrm{~h}$, since it had been observed previously that the product $\mathbf{4 a}$ is converted to 3a with prolonged reaction time (Table 5, entries 1 and 4). Under these conditions ( 1.0 equiv Eco-Ni, $120^{\circ} \mathrm{C}, 2 \mathrm{~h}$ ), the conversion reached $100 \%$, but the selectivity towards the chlorinated product $\mathbf{4 a}$ was very low (Table 6 , entry 2 ). In turn, using 0.5 equiv of $\mathrm{Ni}$ from $\mathrm{Eco}-\mathrm{Ni}$, allowed us to conserve the high conversion and to improve the selectivity towards the desired chlorinated product 4a (64\% yield, Table 6, entry 3). Thus, it can be concluded that the poor selectivity observed when using 1.0 equivalent of $\mathrm{Ni}$ originated from the large amount of $\mathrm{Ni}$ present, which led to the formation of undesired verdyl acetate $\mathbf{3 a}$ at the cost of $\mathbf{4 a}$.
Further optimization of the reaction with 0.5 equiv of $\mathrm{Ni}$ led to the isolation of desired chlorinated product $4 \mathrm{a}$ with $68 \%$ yield when the reaction time was $1 \mathrm{~h}$ (Table 6 , entries 3-5). So far the reactions were conducted with the use of 3 equiv of acetic acid, in order to maintain comparable conditions to those applied for Eco-Zn. However, since the application of Eco$\mathrm{Ni}$ focused on the formation of chlorinated product $\mathbf{4 a}$, acetic acid could probably be superfluous. We therefore carried out an experiment without the acetic acid and under optimal conditions for the formation of product $4 \mathrm{a}$ ( $\mathrm{Ni} 0.5$ equiv, $120^{\circ} \mathrm{C}, 2 \mathrm{~h}$ ). Surprisingly, the desired product $4 \mathrm{a}$ was isolated only with $29 \%$ yield (Table 6, entry 6). It therefore appears that the presence of acetic acid is required in the reaction with Eco-Ni if chlorinated product $\mathbf{4 a}$ is to be obtained with good yield. It is possible that acetic acid plays a role in the process of releasing of $\mathrm{HCl}$ from $\mathrm{Eco}-\mathrm{Ni}$, e.g., by stabilizing the metal ions resulting from departure of $\mathrm{Cl}$, to which chlorine was attached in the Eco-Ni before reaction. However, the amount of acetic acid could be reduced to 1 equivalent maintaining the good yield of the desired chlorinated product 4a (Table 6,

Table 5 Hydro-acyloxy-addition reaction catalyzed by Eco-Zn catalyst: optimization of the reaction conditions

\begin{tabular}{|c|c|c|c|c|c|c|c|c|}
\hline Entry $^{a}$ & $\begin{array}{l}\text { Equiv. of } \\
\mathrm{AcOH}\end{array}$ & $\begin{array}{l}\text { Solid } \\
\text { medium }\end{array}$ & $\begin{array}{l}\mathrm{T} \\
\left({ }^{\circ} \mathrm{C}\right)\end{array}$ & $\begin{array}{l}\mathrm{mol} \% \text { of } \mathrm{Zn} \\
\text { from Eco- } \mathrm{Zn}\end{array}$ & $\begin{array}{l}\text { Time } \\
\text { (h) }\end{array}$ & $\begin{array}{l}\text { Conversion } \\
(\%)^{\mathrm{b}}\end{array}$ & Yield $(\%)^{b}$ & \\
\hline & & & & & & & $3 a$ & $4 a$ \\
\hline 1 & 3 & - & 120 & 10 & 4 & 87 & 37 & 50 \\
\hline 2 & 3 & - & 60 & 10 & 4 & 6 & 1 & 5 \\
\hline 3 & 3 & - & 120 & $10^{\mathrm{c}}$ & 4 & 100 & 98 & 2 \\
\hline 4 & 3 & - & 120 & 10 & 24 & 99 & 71 & 28 \\
\hline 5 & 3 & $\mathrm{SiO}_{2}{ }^{\mathrm{d}}$ & 120 & 10 & 12 & 100 & 89 & 11 \\
\hline 6 & 1 & $\mathrm{SiO}_{2}{ }^{\mathrm{d}}$ & 120 & 10 & 12 & 100 & 84 & 16 \\
\hline 7 & 1 & $\mathrm{SiO}_{2}{ }^{\mathrm{d}}$ & 120 & 0 & 12 & 17 & 17 & 0 \\
\hline 8 & 1 & $\mathrm{SiO}_{2}{ }^{\mathrm{d}}$ & 120 & 1 & 12 & 99 & 87 & 12 \\
\hline 9 & 1 & $\mathrm{SiO}_{2}{ }^{\mathrm{d}}$ & 120 & $1^{\mathrm{e}}$ & 12 & 85 & 72 & 13 \\
\hline 10 & 1 & $\mathrm{SiO}_{2}{ }^{\mathrm{d}}$ & 120 & $1^{\mathrm{f}}$ & 12 & 73 & 62 & 11 \\
\hline
\end{tabular}

\footnotetext{
${ }^{\mathrm{a}}$ Reaction performed on $1.0 \mathrm{mmol}$ of dicyclopentadiene

${ }^{\mathrm{b}}$ Conversion and yield were determined by GC-MS with biphenyl as internal standard

${ }^{\mathrm{c}}$ Commercial $\mathrm{ZnCl}_{2}$ was used as the source of $\mathrm{Zn}$

${ }^{\mathrm{d}} \mathrm{A} 1.0 \mathrm{~g}$ of $\mathrm{SiO}_{2}$ was used as solid medium

${ }^{\mathrm{e}}$ Catalyst recycled one time

${ }^{\mathrm{f}}$ Catalyst recycled two times
} 
Scheme 2 Products obtained with the Eco-Zn catalyst
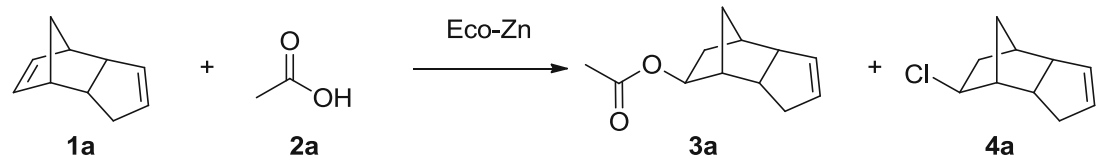

$4 a$ entry 7) and even better ratio of products $\mathbf{4 a / 3 a}(\mathbf{4 a} / \mathbf{3 a}: \mathbf{7 0 / 1 0}$, Table 6, entry 7) than that obtained with the of 3 equiv of acetic acid (4a/3a: 68/23, Table 5, entry 4) (which is a consequence of the use of an excess of acetic acid, favoring the formation of the acetate $\mathbf{3 a}$ ).

Additionally, we have tested this reaction under solventfree conditions with addition of silica gel as a dispersing agent (in order to provide a better homogenization of the reaction medium). Under those conditions, the chlorinated product $4 \mathbf{a}$ was obtained with $69 \%$ yield (Table 5, entry 8), which is comparable to the results obtained without the addition of silica gel (Table 5 , entry 7). Ratio of products $\mathbf{4 a / 3} \mathbf{3}$ however was slightly lower (4a/3a: 69/29). Extending the reaction time to $5 \mathrm{~h}$ did not improve those results (Table 5, entry 9). Therefore, the use of a solid dispersant is not as advantageous in the case of the formation of chlorinated product $4 \mathbf{a}$ with Eco-Ni, as it was in the case of formation of verdyl acetate $\mathbf{3 a}$ with Eco-Zn (see Table 5).

Finally, a reaction carried out under the optimized conditions (Ni 0.5 equiv, $120^{\circ} \mathrm{C}, 1 \mathrm{~h}$ ), but with a commercial nickel chloride (Table 6, entry 10) led to a lower yield of $4 \mathbf{a}$ than that observed with the use of Eco-Ni (45\% yield with the use of $\mathrm{NiCl}_{2} \cdot 6 \mathrm{H}_{2} \mathrm{O}$ versus $69 \%$ yield with the use of Eco-Ni; Table 6 , entry 8 ). These observations show that the results obtained with Eco-Ni depend directly on the nature of the plant-based extract, whose constituents have unique and specific properties in organic synthesis. The Eco-Ni catalyst thus provides a synthetic pathway for green and efficient synthesis of compound $\mathbf{4 a}$, which may serve as a precursor in organic synthesis, especially in coupling reactions that frequently involve the use of halogenated compounds.

\section{Comparison of the catalytic activity of Eco-Zn with Eco-Ni}

Having in our hand the optimized conditions for the hydroacyloxy-addition reaction catalyzed by Eco-Zn and Eco-Ni, we have applied this protocol to different substrates, in order to examine the reaction scope and limitations (Table 7). As depicted on Fig. 6 and in Table 7, reactions with Eco-Zn allowed selective preparation of esters $\mathbf{3 a}-\mathbf{h}$ whereas the use of Eco-Ni yielded selectively the chlorinated products $\mathbf{4 a - c}$.

Reaction between cyclohexane $\mathbf{1 b}$ and acetic acid 2a is a good illustration of the tendency observed during the preliminary optimization of the reaction conditions with the use of dicyclopentadiene as substrate. When optimized conditions favoring the formation of acetate with Eco-Zn were used $\left(1 \mathrm{~mol} \%, 120^{\circ} \mathrm{C}, 24 \mathrm{~h}\right)$, the desired acetate $\mathbf{3 b}$ was obtained with $71 \%$ yield (Table 7 , entry 1 ). In turn, application of the

Table 6 Hydro-acyloxy-addition reaction catalyzed by Eco-Ni catalyst: optimization of the reaction conditions

\begin{tabular}{|c|c|c|c|c|c|c|c|c|}
\hline Entry $^{\mathrm{a}}$ & $\begin{array}{l}\text { Equiv. of } \\
\text { AcOH }\end{array}$ & $\begin{array}{l}\text { Solid } \\
\text { medium }\end{array}$ & $\mathrm{T}\left({ }^{\circ} \mathrm{C}\right)$ & Equiv of $\mathrm{Ni}$ from $\mathrm{Eco}-\mathrm{Ni}$ & $\begin{array}{l}\text { Time } \\
\text { (h) }\end{array}$ & $\begin{array}{l}\text { Conversion } \\
(\%)^{b}\end{array}$ & Yield $(\%)^{\mathrm{b}}$ & \\
\hline & & & & & & & $3 a$ & $4 a$ \\
\hline 1 & 3 & - & 120 & 0.1 & 4 & 58 & 14 & 44 \\
\hline 2 & 3 & - & 120 & 1.0 & 2 & 100 & 52 & 48 \\
\hline 3 & 3 & - & 120 & 0.5 & 2 & 99 & 35 & 64 \\
\hline 4 & 3 & - & 120 & 0.5 & 1 & 91 & 23 & 68 \\
\hline 5 & 3 & - & 120 & 0.5 & 0.5 & 76 & 16 & 60 \\
\hline 6 & 0 & - & 120 & 0.5 & 2 & 29 & 0 & 29 \\
\hline 7 & 1 & - & 120 & 0.5 & 1 & 80 & 10 & 70 \\
\hline 8 & 1 & $\mathrm{SiO}_{2}{ }^{\mathrm{c}}$ & 120 & 0.5 & 1 & 98 & 29 & 69 \\
\hline 9 & 1 & $\mathrm{SiO}_{2}{ }^{\mathrm{c}}$ & 120 & 0.5 & 5 & 100 & 36 & 63 \\
\hline 10 & 1 & $\mathrm{SiO}_{2}{ }^{\mathrm{c}}$ & 120 & $0.5^{\mathrm{d}}$ & 1 & 73 & 28 & 45 \\
\hline
\end{tabular}

\footnotetext{
${ }^{\mathrm{a}}$ Reaction performed on $1.0 \mathrm{mmol}$ of dicyclopentadiene

${ }^{\mathrm{b}}$ Conversion and yield were determined by GC-MS with biphenyl as internal standard

${ }^{\mathrm{c}} \mathrm{A} 1.0 \mathrm{~g}$ of $\mathrm{SiO}_{2}$ was used as solid medium

${ }^{\mathrm{d}}$ Commercial $\mathrm{NiCl}_{2} \cdot 6 \mathrm{H}_{2} \mathrm{O}$ was used as source of $\mathrm{Ni}$
} 
Table 7 Eco-Zn- and Eco-Ni-catalyzed hydro-acyloxy-addition reaction with the use of various substrates

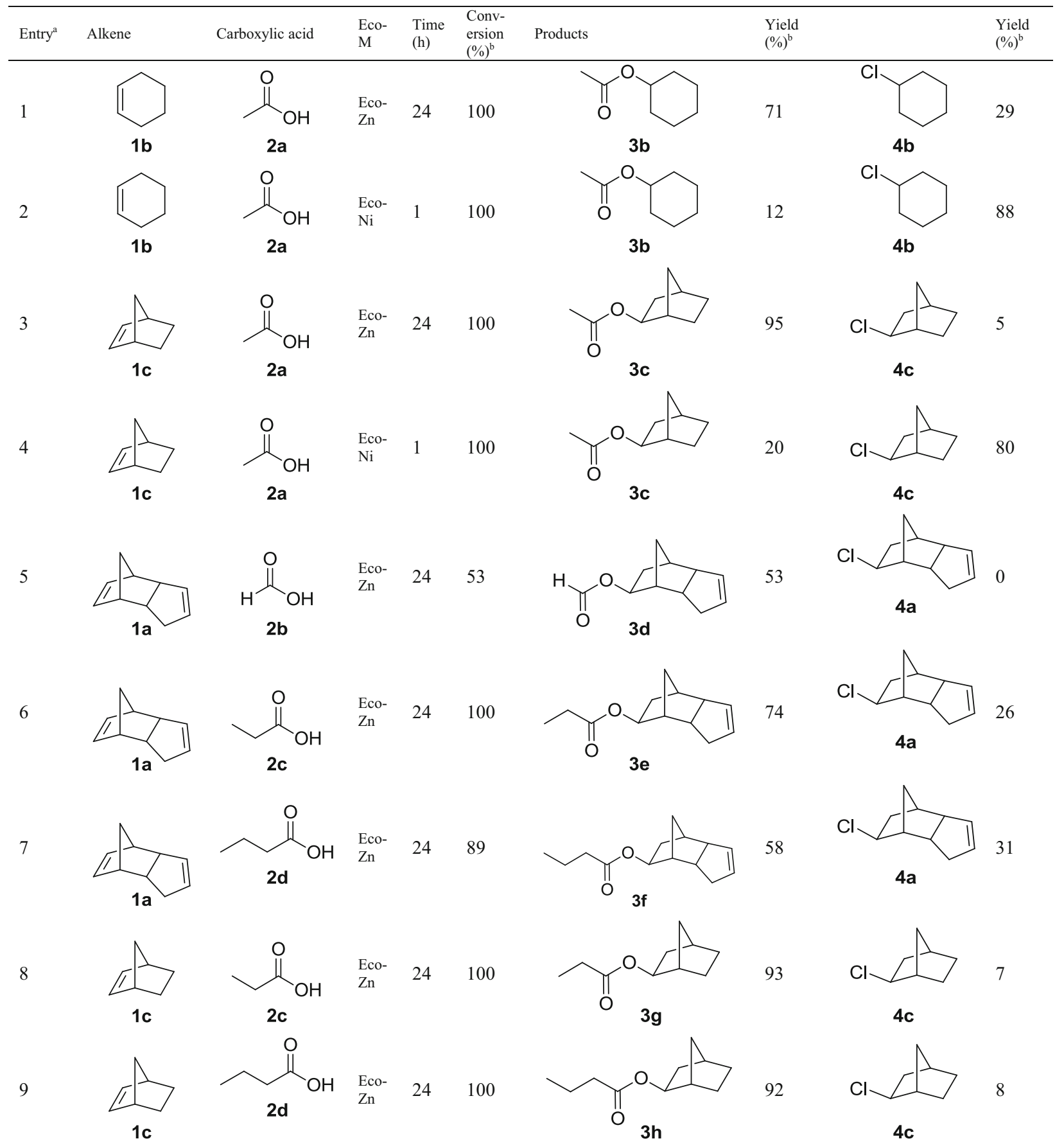

${ }^{\text {a }}$ Reaction conditions : alkene (1.0 mmol), carboxylic acid (1.0 mmol), Eco-Zn (10 mg, amount corresponding to $0.01 \mathrm{mmol}$ of Zn, according to ICP-MS analysis) or Eco-Ni (entries 2 and 4) $\left(385 \mathrm{mg}\right.$, amount corresponding to $0.5 \mathrm{mmol}$ of Ni, according to ICP-MS analysis), and silica gel (1.0 g), $120{ }^{\circ} \mathrm{C}$ ${ }^{\mathrm{b}}$ Conversion and yield were determined by GC-MS with biphenyl as internal standard

optimized conditions for the formation of chlorinated product with Eco-Ni $\left(0.5\right.$ equiv, $\left.120^{\circ} \mathrm{C}, 1 \mathrm{~h}\right)$ produced the desired product $\mathbf{4 b}$ with $88 \%$ yield (Table 7 , entry 2). Similarly, reaction with the use of norbornene $1 \mathbf{c}$, as alkene, furnished selectively the acetate $\mathbf{3 c}(95 \%$ yield, Table 7 , entry 3$)$ with the use of Eco-Zn and the chlorinated product $4 \mathbf{c}$ ( $80 \%$ yield,
Table 7, entry 4) with the use of Eco-Ni catalyst. Subsequently, various carboxylic acids were tested in order to check the possibility to produce different esters. Reaction with formic acid $\mathbf{2 b}$ and dicyclopentadiene $\mathbf{1 a}$ produced the desired ester $\mathbf{3 b}$ with $53 \%$ yield. Formation of the corresponding chlorinated product 4a was not observed (Table 7, entry 
Fig. 6 Selective formation of product $3 \mathbf{a}$ or $4 \mathbf{a}$ depending on the nature of the ecocatalysts used

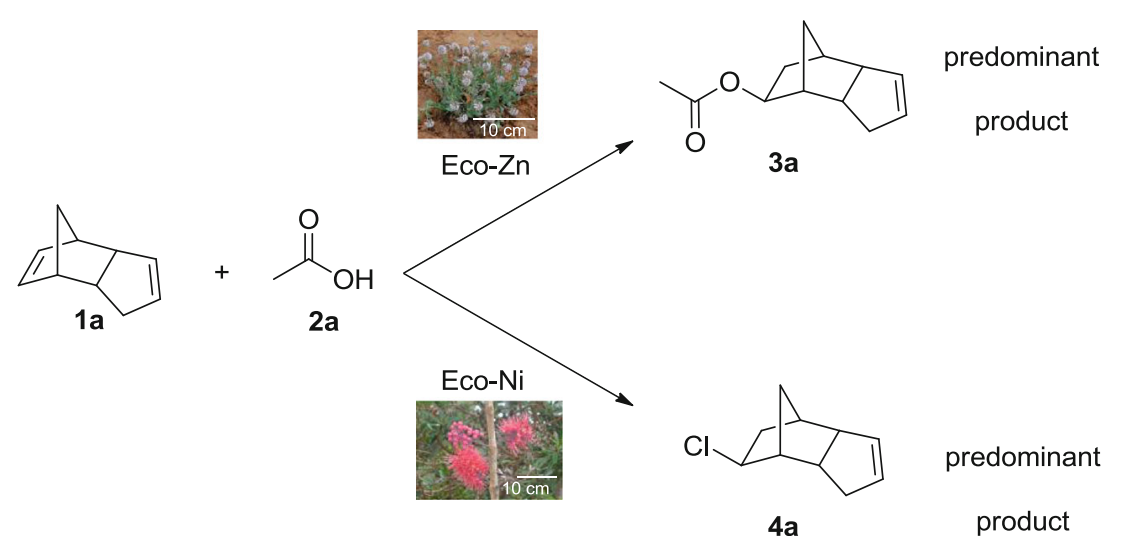

original compositions and properties of the ecocatalysts, whose reactivity thus correlates with the botanical origin of the metal-hyperaccumulating plant. Phytoextraction proves therefore to be useful not only for the environment but also for organic chemistry. This constitutes an encouragement to develop phytoextraction for the recovery of degraded sites, by giving a new scientific and economic value to the resulting biomass.

Acknowledgments The authors would like to thank the Agence Nationale de la Recherche (ANR, programme 11ECOT 011 01), the Agence de l'Environnement et de la Maîtrise de l'Energie (ADEME), the Centre National de la Recherche Scientifique (CNRS) and the Fond Européen de Développement Régional (FEDER) for financial support.

\section{References}

Adams JP, Alder CM, Andrews I, Bullion AM, Campbell-Crawford M, Darcy MG, Hayler JD, Henderson RK, Oare CA, Pendrak I, Redman AM, Shuster LE, Sneddon HF, Walker MD (2013) Development of GSK's reagent guides - embedding sustainability into reagent selection. Green Chem 15:1542-1549

Anderson CWN (2013) Hyperaccumulation by plants. In: Hunt AJ (ed) Element recovery and sustainability. The Royal Society of Chemistry, Cambridge, pp 114-139

Annby U, Stenkula M, Andersson CM (1993) Regiochemistry of palladium(II)-assisted oxidative lactonization reactions. Tetrahedron Lett 34:8545-8548

Ballantine JA, Davies M, Purnell H, Rayanakorn M, Thomas JM, Williams KJ (1981) Chemical Conversions Using Sheet Silicates Facile Ester Synthesis by Direct Addition of Acids to Alkenes. Journal of the Chemical Society-Chemical Communications, 8-9

Bhargava A, Carmona FF, Bhargava M, Srivastava S (2012) Approaches for enhanced phytoextraction of heavy metals. J Environ Manag 105:103-120

Bridge G (2004) Contested terrain: mining and the environment. Annu Rev Environ Resour 29:205-259

Chaney RL, Li Y-M, Brown SL, Homer FA, Malik M, Angle JS, Baker AJM, Reeves RD, Chin M (2000) In: Terry N (ed) Phytoremediation of contaminated soil and water. CRC Press, Boca Raton

Chen WY, Lu J (2007) In (OTf) (3)-catalyzed intermolecular addition of carboxylic acids and phenols to norbornene under solventfree conditions. Catal. Commun. 8:1298-1300 
Choi JC, Kohno K, Masuda D, Yasuda H, Sakakura T (2008) Ironcatalysed green synthesis of carboxylic esters by the intermolecular addition of carboxylic acids to alkenes. Chem Commun (Cambridge, U K), 777-779

Dobbs DA, Vanhessche KPM, Brazi E, Rautenstrauch V, Lenoir J-Y, Genêt J-P, Wiles J, Bergens SH (2000) Industrial synthesis of (+)cis-methyl dihydrojasmonate by enantioselective catalytic hydrogenation; identification of the precatalyst $[\mathrm{Ru}((-)-\mathrm{Me}-$ DuPHOS $)(\mathrm{H})(\eta 6-1,3,5$-cyclooctatriene)](BF4). Angew Chem Int Ed 39:1992-1995

Escande V, Garoux L, Grison C, Thillier Y, Debart F, Vasseur J-J, Boulanger C, Grison C (2014a) Ecological catalysis and phytoextraction: symbiosis for future. Appl Catal B 146:279-288

Escande V, Olszewski TK, Grison C (2014b) Preparation of ecological catalysts derived from $\mathrm{Zn}$ hyperaccumulating plants and their catalytic activity in Diels-Alder reaction. C R Chim. 17:731-737

Escande V, Olszewski TK, Petit E, Grison C (2014c) Biosourced polymetallic catalysts: an efficient means to synthesize underexploited platform molecules from carbohydrates. ChemSusChem. 7: 1915-1923

Federsel H-J (2013) En route to full implementation: driving the green chemistry agenda in the pharmaceutical industry. Green Chem 15: 3105-3115

Ferraz HMC, Ribeiro CMR (1992) Thallium (III) salts-induced lactonizations of unsaturated carboxylic-acids. Synth Commun 22: 399-404

Grison C, Bès C (2013) Techniques de dépollution. In: Euzen A, Eymard $\mathrm{L}$, Gaill $\mathrm{F}$ (eds) Le développement durable à découvert. CNRS Editions, Paris, p 264

Grison C, Escande V (2013a) Use of certain manganese-accumulating plants for carrying out organic chemistry reactions. WO 2014/ $016509 \mathrm{~A} 1$

Grison C, Escande V (2013b) Use of certain metal-accumulating plants for implementing organic chemistry reactions. WO 2013150197 A1

Grison C, Escande V (2014) Use of particular metal accumulating plants for implementing catalyzed chemical reactions PCT/EP2014/ 053485

Grison C, Escarré J (2011) Use of metal-accumulating plants for the preparation of catalysts that can be used in chemical reactions. patent references: WO2011/064487A1 ; PCT/FR2010/052451 ; CA2781832-A1; EP2504096-A1

Grison C, Escande V, Petit E, Garoux L, Boulanger C, Grison C (2013) Psychotria douarrei and Geissois pruinosa, novel resources for the plant-based catalytic chemistry. RSC Adv 3:22340-22345

Gu YL, Shi F, Deng YQ (2004) Esterification of aliphatic acids with olefin promoted by Brønsted acidic ionic liquids. J Mol Catal A Chem 212:71-75

He Y, Goldsmith CR (2010) The halogenation of aliphatic C-H bonds with peracetic acid and halide salts. Synlett 2010:1377-1380

Hinze R, Laufer MC, Holderich WF, Bonrath W, Netscher T (2009) The use of Nafion/silica composite catalysts for synthesis of fine chemicals. Catal Today 140:105-111

Horiuchi CA, Fukushima T, Furuta N, Chai W, Ji SJ, Saito Y, Hashimoto C, Takahashi TT, Sugiyama T, Muto A, Sakata Y, Nozaki S (2003) Esterification of alkene with cerium(IV) sulfate in carboxylic acid. Journal of Chemical Research-S, 270-272

Hunt AJ, Farmer TJ, Clark JH (2013) Chapter 1 - elemental sustainability and the importance of scarce element recovery, element recovery and sustainability. The Royal Society of Chemistry, pp. 1-28

Kobayashi S, Busujima T, Nagayama S (2000) A novel classification of Lewis acids on the basis of activity and selectivity. Chem Eur J 6: 3491-3494

Kraft P, Swift KAD, Royal Society of Chemistry (Great Britain), Society of Chemical Industry (Great Britain) (2005) Perspectives in flavor and fragrance research. Helvetica Chimica Acta; Wiley-VCH, Zurich, Weinheim, viii, 242 p. pp
Krishna K, Seijger GBF, van den Bleek CM, Makkee M, Mul G, Calis HPA (2003) Selective catalytic reduction of NO with NH3 over FeZSM-5 catalysts prepared by sublimation of $\mathrm{FeCl} 3$ at different temperatures. Catal Lett 86:121-132

Larock RC, Hightower TR (1993) Synthesis of unsaturated lactones via palladium-catalyzed cyclization of alkenoic acids. J Org Chem 58: 5298-5300

Leseurre L, Merea C, Duprat de Paule S, Pinchart A (2014) Eco-footprint: a new tool for the "Made in Chimex" considered approach. Green Chem 16:1139-1148

Li ZG, Zhang JL, Brouwer C, Yang CG, Reich NW, He C (2006) Bronsted acid catalyzed addition of phenols, carboxylic acids, and tosylamides to simple olefins. Org. Lett. 8, 4175-4178

Lloyd L (2011) Handbook of industrial catalysts. Springer Science + Business Media, New York

Magens S, Ertelt M, Jatsch A, Plietker B (2007) A nucleophilic Fe catalyst for transesterifications under neutral conditions. Org Lett 10:53-56

Matus KJM, Zimmerman JB, Beach E (2010) A Proactive approach to toxic chemicals: moving green chemistry beyond alternatives in the "Safe Chemicals Act of 2010". Environ Sci Technol 44:6022-6023

Mondelli C, Amrute AP, Schmidt T, Perez-Ramirez J (2011) A delafossite-based copper catalyst for sustainable $\mathrm{Cl}_{2}$ production by $\mathrm{HCl}$ oxidation. Chem Commun (Camb, U K) 47: $7173-7175$

Parry EP (1963) An infrared study of pyridine adsorbed on acidic solids. Characterization of surface acidity. J Catal 2:371-379

Patnaik P (2003) Potassium chlorate. Handbook of inorganic chemicals. McGraw-Hill, New York, pp 745-746

Peterson PE (1960) Solvents of low nucleophilicity.I. Reactions of hexyl tosylates and hexenes in trifluoroacetic acid and other acids. J Am Chem Soc 82:5834-5837

Peterson PE, Allen G (1962) Solvents of low nucleophilicity. II. Addition of trifluoroacetic acid to alkenes and cycloalkenes. J Org Chem 27: $1505-1509$

Peterson PE, Allen G (1963) Solvents of low nucleophilicity. III. Effect of remote substituents in addition of trifluoroacetic acid to substituted alkenes. J Am Chem Soc 85:3608-3613

Peterson PE, Tao EVP (1964) Solvents of low nucleophilicity. IV. Addition of acetic formic, and trifluoroacetic acid to branched alkenes. J Org Chem 29:2322-2325

Raskin I, Ensley BD (2000) Phytoremediation of toxic metals, using plants to clean up the environment. John Wiley and Sons, Inc, New York

Rosenfeld DC, Shekhar S, Takemiya A, Utsunomiya M, Hartwig JF (2006) Hydroamination and hydroalkoxylation catalyzed by triflic acid. Parallels to reactions initiated with metal triflates. Org. Lett. 8: 4179-4182

Salazar K (2013) Mineral Commodity Summaries 2013: US Geological Survey (USGS). US Geological Survey

Satchell DPN, Satchell RS (1969) Quantitative aspects of the Lewis acidity of covalent metal halides and their organo derivatives. Chem Rev 69:251-278

Saunier JB, Losfeld G, Freydier R, Grison C (2013) Trace elements biomonitoring in a historical mining district (les Malines, France). Chemosphere 93:2016-2023

Schmidt H, BurtzlaffC, Masuhr H, Ohl J, Pehle W, Schmoz G, Suppan R, Tetzner W (1980) Reactions of difluorodichloromethane with hydrocarbons. J Prakt Chem 322:751-760

Sell CS (2006) Perfume ingredients derived from dicyclopentadiene. The chemistry of fragrances from perfumer to consumer. RSC Publishing, Cambridge, UK, pp 129-131

Singh OV, Labana S, Pandey G, Budhiraja R, Jain RK (2003) Phytoremediation: an overview of metallic ion decontamination from soil. Appl Microbiol Biotechnol 61:405-412 
Taylor JG, Whittall N, Hii KKM (2005) Copper(II)-catalysed addition of $\mathrm{O}-\mathrm{H}$ bonds to norbornene. Chem Commun (Cambridge, $\mathrm{U} \mathrm{K}$ ), 5103-5105

Thornton I (1996) Impacts of mining on the environment; some local, regional and global issues. Appl Geochem 11:355-361

United Nations Environment Programme (UNEP), United Nations University (2009) Critical metals for future sustainable technologies and their recycling potential

Wang B, Gu YL, Yang LM, Suo JS, Kenichi O (2004) Sulfamic acid as a green, efficient, recyclable and reusable catalyst for direct addition of aliphatic acid with cyclic olefins. Catal Lett 96:70-74

Watson WJW (2012) How do the fine chemical, pharmaceutical, and related industries approach green chemistry and sustainability? Green Chem 14:251-259
Wilson M, Schwarzman M (2009) Toward a new U.S. Chemicals Policy: rebuilding the foundation to advance new science, green chemistry, and environmental health. Environ Health Perspect 117:1202-1209

Wunderly HL, Sowa FJ (1937) The condensation of acetic acid and cyclohexene in the presence of boron fluoride. J Am Chem Soc 59:1010-1011

Yamamoto H (2000) Lewis acids in organic synthesis. WILEY-VCH Verlag $\mathrm{GmbH}$, Weinheim

Yang T, Wen XD, Li JF, Yang LM (2006) Theoretical and experimental investigations on the structures of purified clay and acidactivated clay. Appl. Surf. Sci. 252:6154-6161

Zaki MI, Hasan MA, Al-Sagheer FA, Pasupulety L (2001) In situ FTIR spectra of pyridine adsorbed on $\mathrm{SiO}_{2}-\mathrm{Al}_{2} \mathrm{O}_{3}, \mathrm{TiO}_{2}, \mathrm{ZrO}_{2}$ and $\mathrm{CeO}_{2}$ : general considerations for the identification of acid sites on surfaces of finely divided metal oxides. Colloids Surf A Physicochem Eng Asp 190:261-274 